\title{
Representaciones sociales sobre la práctica de aprovisionamiento de personal en docentes de educación superior en Colombia
}

\author{
Yadid Estela Paternina Avilez ${ }^{1}$ \\ Fecha: Recibido noviembre 15 de 2014 - Aceptado diciembre 10 de 2014
}

\begin{abstract}
Resumen
En esta investigación se fijó como objetivo conocer las representaciones sociales sobre la práctica de aprovisionamiento de personal de un grupo de trabajadores académico - administrativos de una institución de educación superior en Colombia, con la aplicación de una metodología cualitativa utilizando la entrevista en profundidad y el grupo focal. Los hallazgos de esta investigación, muestran resultados interesantes para docentes, IES, académicos y gerentes del talento humano; abre tantos nuevos interrogantes como opciones de estudio en profundidad, sobre la satisfacción de los docentes universitarios y la necesidad de inclusión de la gestión humana en la política nacional que rige el sistema de calidad de la educación superior en Colombia.
\end{abstract}

Palabras clave: aprovisionamiento de personal, gerencia del talento humano, representaciones sociales y docente universitario.

\section{Social representations about the practice of teachers' recruitment in Higher Education in Colombia}

\begin{abstract}
In this research we set the goal to understand the social representations practice of staffing of a group of academic workers - administration of an institution of higher education in Colombia, with the application of a qualitative methodology using in-depth interviews and group focal. The findings of this research show interesting results for teachers, IES, academics and Human Resource Managers, opens new questions as options both in-depth study on satisfaction of university teachers and the need for inclusion of human management in politics national governing the quality system of higher education in Colombia.
\end{abstract}

Keywords: procurement staff, human resource management, social representations and university teaching.

${ }^{1}$ Psicóloga, Especialista y Magíster en Gerencia del Talento Humano de la Universidad de Manizales. Docente Investigadora de la Corporación Universitaria del Caribe - CECAR. yadith.paternina@cecar.edu.co 
BÚSQUEDA - Julio / Diciembre de 2014 - No. 13 (111 - 120)

\section{Introducción}

En la actualidad de las organizaciones, incluidas en ellas las instituciones de educación superior, se presentan exigencias y retos propios de un ambiente globalizado, altamente cambiante y complejo, aspectos que difícilmente pueden abordarse sin el valor que agregan las personas.

La creación de valor y sostenimiento de las instituciones depende en buena medida de la aplicación de prácticas de gestión humana y más específicamente, de la forma cómo se atrae y retiene el talento más idóneo.

En la vida social de las organizaciones se construye conocimiento a través de procesos representacionales, y de este saber, se derivan actitudes, opiniones, expectativas, sentimientos y vivencias importantes para el comportamiento laboral.

En este orden de ideas, comprender las representaciones sociales sobre la práctica de aprovisionamiento en docentes de educación superior permite hacer un acercamiento a las concepciones, imágenes, valores y mitos que se forjan en este grupo.

Dado que las investigaciones relevantes en materia de gestión humana (Calderón, Montes \& Tobón, 2004; Calderón \& Álvarez, 2006), han revelado una situación problemática; que los estudios han tenido como informantes a los empresarios, quienes aseguran que la manera intuitiva de contratar les da resultados y que creen en la garantía de idoneidad que ofrece la hoja de vida y que además, las formas intuitivas de aprovisionamiento investigadas, se han usado en organizaciones donde el personal requerido es de baja cualificación. Esta investigación se centró en comprender las representaciones sociales de la práctica de aprovisionamiento en docentes de una institución de educación superior en Colombia.

Escenario actual de la gerencia del talento humano
En la actualidad, el ámbito de las empresas en el contexto global se enmarca en procesos de transformación económicos, políticos, sociales y culturales; la dinámica de las organizaciones a nivel mundial exige ir a la par de los sucesos de modernización. El ser humano inmerso en esta realidad se convierte en el centro y principal receptor del cambio, lo que genera en primera instancia, caos, tanto en las empresas como en la vida de las personas; de igual forma es innegable que estos procesos obligan al replanteamiento de las teorías empresariales y la posición frente al mundo.Al respecto, afirma Marín (2004) que la sociedad del conocimiento trae consigo grandes y traumáticos desafíos, basados en los nuevos paradigmas que exigen liderazgos que sean capaces de ser interpretados y encauzados hacia la construcción de un orden social en el que el desarrollo tenga como fin, mejorar la calidad de vida de los seres humanos que la integran.

Conceptualización, evolución, retos y tendencias de la gestión del talento humano.

Calderón, Álvarez y Naranjo (2006b), realizan un recorrido por las perspectivas de trabajo clásica, neoclásica y economicista, donde logra inferirse el papel del capital humano en una organización, en lo relacionado con el aporte en el progreso de los diferentes procesos que se llevan al interior de ella.

Frente a este panorama, los procesos que se desarrollanal interior de las organizaciones cumplen un papel fundamental al potencializar el factor humano a través de las prácticas y su necesaria alineación con la estrategia organizacional.

Saldarriaga (2008), aporta sobre las tendencias y perspectivas de la gestión humana, haciendo un acercamiento al quehacer de ésta. Referencia algunos autores que muestran concepciones sobre esta área, lo que permite así dimensionar y analizar el inmenso reto para las organizaciones de hoy y que se proyectan hacia el futuro.

\section{Prácticas de gestión humana}

Las prácticas de gestión humana son entendidas por Ulrich y Lake (1992) como 
Yadid Estela Paternina Avilez - Representaciones sociales sobre la práctica de aprovisionamiento

procesos más o menos formales que las organizaciones desarrollan para orientar la acción y la dirección empresarial e incidir sobre el comportamiento de las personas. Son establecidas a partir de los objetivos de la organización, su estructura, las jerarquías y los modelos gerenciales predominantes; están afectadas por el tamaño de la entidad, la forma de propiedad, el entorno inmediato y la cultura empresarial (Calderón, Montes \& Tobón (2004).

En general, tales prácticas en el modelo capitalista se han orientado al mantenimiento de las relaciones de producción y han sido colonizadas por las exigencias del mercado y de la visión economicista de los negocios (Alonso, 1999).

\section{Aprovisionamiento de personal}

El aprovisionamiento de personal comprende tres prácticas diferenciadas - el reclutamiento, la selección y la contratación. Valle, (2004) reporta que en las fases iníciales del desarrollo de la gestión humana esta fue una etapa burocrática para "llenar vacantes", pero, que dada la presión para atraer talentos y competencias, se ha ido convirtiendo en una actividad trascendental para las organizaciones.

Antes de los años ochenta, los criterios de selección se enfocaron a aspectos socios culturales como la capacidad de adaptación, las "buenas costumbres", el sometimiento a la disciplina, la ausencia de experiencia sindical (López, 1999) citado por Calderón et al., (2007). El incremento de la cobertura en la educación, llevó a que las empresas pudieran reclutar personas con mayor nivel académico, pero en los noventa con el nuevo modelo tecno- económico, que reconoce el valor del conocimiento como fuente de valor agregado, hacen que las empresas tomaran conciencia de la necesidad de cambiar la manera de seleccionar sus trabajadores.

Un aspecto importante es conocer si en los procesos de selección se privilegian criterios técnicos (conocimientos y habilidades), sociohumanísticos o de proyección. En el primer caso se hará énfasis en pruebas y certificaciones que permitan valorar la aptitud técnica del candidato para desempeñar el cargo; en el segundo, se tratarán de detectar relaciones interpersonales, posibilidad de encajar en los valores y cultura de la organización, calidad humana, capacidad de adaptación al ambiente interno, posibilidad de trabajar sin supervisión, entre otras (Pfeffer, 1996 y 1998; Gubman (2000).

\section{Representaciones sociales}

La noción de Representación social es un eje fundamental para la investigación. La teoría de las Representaciones sociales es una valiosa herramienta dentro y fuera del ámbito de la Psicología Social porque ofrece un marco explicativo acerca de los comportamientos de las personas estudiadas.

Originalmente, Moscovici (1979), citado por Rodríguez, (2009), llama la atención sobre la complejidad del pensamiento de sentido común, abre la posibilidad de estudiar cómo distintas cogniciones y creencias culturales se organizan jerárquicamente para comprender un objeto en un grupo social dado, y destaca los procesos sociales de comunicación y discurso en que surgen, se afianzan y se transforman. Por otro lado, (Moscovici, 1988, citado por Rodríguez, 2009) para interpretar la teoría de las Representaciones sociales como el estudio de "la manera cómo grupos sociales (o en una escala más amplia, sociedades o culturas) conceptualizan un objeto material o simbólico", al mismo tiempo que analiza las diferencias manifiestas en esos sistemas de conceptualización dentro de un grupo o entre grupos sociales. También en este referente teórico se alude que la más clara conceptualización de Representaciones Sociales la ofrece Jodelet (1986), citado por Araya, (2002), figura relevante en este campo de estudio:

"En tanto que fenómenos, las representaciones sociales se presentan bajo formas variadas, más o menos complejas. Imágenes que condensan un conjunto de significados; sistemas de referencia que nos permiten interpretar lo que sucede, e incluso, dar un sentido a lo inesperado; categorías que sirven para clasificar las circunstancias, los fenómenos y a los individuos con quienes tenemos algo que ver; teorías que permiten establecer 
BÚSQUEDA - Julio / Diciembre de 2014 - No. 13 (111 - 120)

hechos sobre ellos. Y a menudo, cuando se les comprende dentro de la realidad concreta de nuestra vida social, las representaciones sociales son todo ello junto" (p. 472)

\section{Metodología}

La presente investigación es de tipo descriptiva e interpretativa que utiliza metodología cualitativa. Tiene como objetivo describir e interpretar de manera detallada las representaciones sociales que tiene un grupo de docentes universitarios sobre una práctica de gestión humana, en este caso de aprovisionamiento de personal, en una realidad múltiple, holística y divergente de las instituciones de educación superior. En este sentido, la relación sujeto - objeto es interaccionada e influenciada por factores subjetivos.

La unidad de análisis estuvo conformada por las representaciones sociales (concepciones, imágenes, mitos y valores) sobre la práctica de aprovisionamiento de los docentes de una institución de educación superior. La unidad de trabajo, estuvo conformada por un grupo de docentes seleccionados de manera intencional, teniendo en cuenta la permanencia como docente de la institución no inferior a cinco años, dedicación docente de medio o tiempo completo e interés por participar en la investigación.

Como técnicas de recolección de información se eligieron la entrevista en profundidad y el grupo focal, por considerarse coherentes con la naturaleza del objeto de estudio, el tipo de investigación y los objetivos del mismo.

El material discursivo resultante de las entrevistas y grupo focal se le dio un tratamiento interpretativo, para lo cual se elaboraron matrices de comprensión que permitieran encontrar primero, el carácter central, constituido por aquellos elementos que son importantes, ligados a relatos de procesos históricos institucionales, el contenido representacional conformado por la historia individual, por sus experiencias particulares y sus relaciones contextuales y vivenciales.

\section{Resultados}

La descripción e interpretación de los hallazgos, giranentorno al objeto representacional propuesto: La práctica de aprovisionamiento de personal y sus respectivas categorías: concepciones, imágenes, valores y mitos sobre la práctica de provisión de personal.

\section{Primera categoría: concepciones sobre aprovisionamiento de personal}

En sus relatos, los docentes manifestaron como concepción de aprovisionamiento, un proceso general de carácter institucional que contempla filtros, perfiles y requisitos que un candidato debe cumplir para que pueda ingresar y contribuir al cumplimiento de los objetivos de la institución, por ejemplo:

"Entiendo la vinculación como la selección de aquellos profesores que según los fines formativos, intereses institucionales se requieren para que lleven a cabo los procesos de formación de estudiantes y otras actividades...La selección debe estar orientada por unos criterios más definidos y se da de acuerdo a los perfiles y a las necesidades de la institución del personal requerido. Toda Universidad debe tener criterios de selección en términos de la experiencia, formación, de la parte pedagógica..."

Sin embargo, el discurso referido a la práctica de aprovisionamiento es percibido con vacíos de referentes frente a los criterios y procesos. "Aquí siento que no hay una estructura clara con respecto al proceso de vinculación, primero siento que no hay claridad con respecto al perfil del cargo de la docencia, adicionalmente al ingresar no se observa un proceso estructurado de selección donde se haga un análisis o evaluación real de las situaciones actuales en las cuales ingresa el docente..."

"En mi vinculación no se hizo un proceso de selección, mi vinculación se dio porque había como un imaginario, pero sin ninguna fundamentación, de que yo me había desempeñado bien en otras partes y debido a ello me llamaron acá, más por referencia fui pasando de un programa para otro. Como no 
hay un proceso de selección cada fin de año tengo que esperar si me llaman o no me llaman".

Emerge en las entrevistas sobre la concepción de aprovisionamiento, una consideración desde la experiencia de algunos docentes, que lo relacionan con un pacto entre partes, equiparándolo al proceso de contratación que tiene como fin la calidad de la educación, como aparece en la siguiente evidencia:

“...La provisión es un protocolo que existe entre dos partes, bien sea natural o jurídica, en donde una se compromete a entregar un bien o un servicio para cumplir las expectativas o necesidades de la otra parte".

Otra tendencia en la concepción de aprovisionamiento está relacionada con procesos de tipo financieros y firma de contrato (formalización contractual y financiera).

Los salarios son un referente importante mencionado por varios docentes entrevistados, quienes hablan de expectativas de mejoras en este aspecto. En estas mismas expectativas se esperan mejores garantías, más beneficios y la mejora en la forma de vinculación. Las perspectivas están radicadas en que algunos aspectos y procesos institucionales puedan mejorar, para permitir la satisfacción de los docentes.

Lo anterior se hace visible en relatos como:

"Yo considero que la contratación hoy es muy regular..., pienso que debe haber una especie de consulta y de balance con lo que pagan en otras universidades y que el salario del docente tenga correspondencia con su categoría, no que se mantenga estable, sino que se le den oportunidades de ascenso..."

La no formalización e institucionalización de un estatuto docente que permita reconocer la formación académica, idoneidad y que pueda colocar así a los docentes en la posibilidad de participar de un plan de carrera al interior de la institución, haciendo que se sientan más valorados y reconocidos.
Como la anterior expectativa no se ha realizado, existe un ambiente, en algunos entrevistados, de insatisfacción que los lleva a la incertidumbre frente a la vinculación en la institución semestre a semestre. Debe entenderse que la institución vincula a sus docentes sin tener en cuenta una política estructurada y por tanto el tiempo fluctúa. La duración del contrato es de cuatro meses para los catedráticos y de diez, once o doce meses para los de medio y tiempo completo.

"Aquí, en docentes de tiempo completo y medio tiempo noto que no hay una uniformidad... para mejorar la calidad, una contratación debería ser indefinida porque así hay más sentido de pertenencia y existe una cualificación y una mejor calidad en los programas porque puede el docente dedicarse a mejorar todos los procesos, y no a cada fin de año con la incertidumbre si vengo o no vengo en el próximo".

Lo anterior, según Jaramillo (2005), lleva a pensar en la necesidad de una gestión del talento humano como un conjunto de procesos necesarios para dirigir a las personas dentro de la organización, partiendo del reclutamiento, selección, capacitación, recompensas, evaluación del desempeño, salud ocupacional y bienestar, entre otros, que conduzcan a la obtención de valor agregado para la institución, los empleados y el entorno, mediante el logro de objetivos de realización y satisfacción de empleados en el trabajo, de ayuda a la institución a alcanzar sus objetivos y realizar su misión, hacerla competitiva, proveer empleados cualificados y motivados; desarrollar y mantener la calidad de vida en el trabajo; y así mismo, gestionar el cambio, establecer políticas éticas y desarrollar comportamientos socialmente responsables.

En resumen, las concepciones de aprovisionamiento, de acuerdo con los relatos, se encuentran en un marco funcional y operativo. Los docentes distinguen la práctica como un proceso deseable y positivo, de responsabilidad administrativa, con una estructura y formalidad. Adicionalmente, en sus concepciones exponen críticas, problemáticas, expectativas y afectos. 
BÚSQUEDA - Julio / Diciembre de 2014 - No. 13 (111 - 120)

Así pues, se puede evidenciar desde estas concepcionesquelapráctica deaprovisionamiento aún no tiene un sentido estratégico, sino eminentemente operativo o funcional, en la que prevalece un proceso intuitivo muy centrado en las referencias personales, quizás con una visión restringida de la gestión humana o quizás desde el asunto que algunos investigadores han llamado la atención, sobre el hecho que muchas empresas concuerdan en afirmar que esta manera intuitiva les da buenos resultados. De esta manera la selección y contratación se concentra en la mayoría de los casos en aspectos humanos y de relaciones, que son estimados muy empíricamente y fundamentados en la experiencia del jefe que haga la entrevista, como lo plantean Calderón y Álvarez, (2006)

Segunda categoría: Imágenes sobre la práctica de aprovisionamiento de personal

Las imágenes asociadas a la práctica de aprovisionamiento del personal docente están relacionadas con la propia vivencia y esta es concebida como negativa, confusa y al margen de la normativa vigente. Evidencia de ello, los participantes hicieron comparaciones, "No hay mucha diferencia entre lo que ocurre aquí y en el ambiente político, donde la vinculación es más por amistad o qué tan bien le caen a la persona que debe tomar la decisión... "y énfasis en la confusión, "Al proceso de selección le falta definirlo más, que se haga realmente de acuerdo con los perfiles $y$ las necesidades, también teniendo en cuenta el programa o la función que le vayan a asignar, pero a veces esa selección se hace de manera arbitraria, no hay unos criterios claros..."

A partir de los relatos de los participantes, se evidencian representaciones de primacía de los intereses patronales frente a las garantías legales, "La contratación es percibida como confusa.... lo que pasa es que funciona más en términos de los ahorros y de los criterios económicos de los directivos que de lo que la Ley está estableciendo".

"Debería darle vida o aplicar el Estatuto Docente, donde no son los títulos, sino la productividad; se quedan con los cartones de las personas y no ven el conocimiento y la productividad de la persona"

"Mi experiencia fue terrible, cuando entré, tuve un problema médico, no estaba afiliada un mes después de estar vinculada y me tocó pagar..."

Lo anterior muestra la necesidad de ampliar el conocimiento traducido en representaciones sociales que sobre la realidad de la provisión tienen y viven los docentes, ya que éste se constituye en un conocimiento del sentido cotidiano y es conocimiento social porque está socialmente elaborado. Incluye contenidos cognitivos, afectivos y simbólicos que tienen una función no solo en ciertas orientaciones de las conductas de las personas en su vida cotidiana, sino también en las formas de organización y comunicación que poseen tanto en sus relaciones interindividuales como entre los grupos sociales en que se desarrollan, en este caso, en el contexto de la institución de educación superior.

Tercera categoría: valores aplicados en la práctica de aprovisionamiento

En este aspecto, más de la mitad de los entrevistados no reconocen que la institución aplique valores en su proceso de vinculación y contratación docente, lo que explicaron como una consecuencia de la confusión e informalidad en el que se percibe la práctica de aprovisionamiento en la institución.

Finalmente, se reporta la falta de transparencia y de respeto en el proceso de vinculación docente, lo que se asocia con impotencia por parte del docente, tal como se relata a continuación: "la contratación es poco transparente y es caótica"

Cuarta categoría: mitos sobre la práctica de aprovisionamiento

Entre la variedad de mitos reportados por los docentes se identifican, en primera instancia, los relacionados con los criterios de selección. Los mitos que se observan con más frecuencia en el proceso de vinculación tienen que ver con el manejo de "roscas" y recomendaciones que influyen en el proceso de vinculación. Lo anterior es relatado como: 
"La amistad con personas con poder, el tráfico de influencia, habilidades de interacción en escenarios públicos y la confianza en la hoja de vida, son los criterios de selección".

Otra categoría está relacionada con los mitos de idoneidad, la mitad de los docentes entrevistados reporta que los títulos y la experiencia mínima o menos que esto generan idoneidad para ser docente; lo que se evidencia en relatos como:

"Se cree que una persona con los mínimos de título y experiencia puede ser un buen docente"

"Se cree que cualquier persona, sin unos mínimos, sin experiencia, puede desempeñarse como docente"

\section{Conclusiones}

Las representaciones sociales emergentes en esta investigación conforman un pensamiento constituido y un pensamiento constituyente, es decir es a la vez, proceso y producto de las formas como los docentes elaboran procesos de construcción de la realidad institucional, desde el momento en que forman parte de ella, contribuyen a configurarla y producen además efectos y valoraciones sobre ésta.

Por el principio de mediación de las representaciones, permite constituir maneras y formas de ser sujetos sociales en la medida en que se comparte una vivencia de identificación con un grupo, una institución o una comunidad, con posturas críticas o acríticas.

Las representaciones sociales derivadas que emegen en esta investigación permiten identificar la necesidad de una reflexión acerca de la institución en sí, de sus objetivos, de la manera como los cumple y de las estrategias que implementa no solo para relacionarse con el entorno, sino también y de manera muy especial, en la forma como sus procesos son asumidos y vivenciados por las personas que la componen. Esto permitirá avanzar en comprensiones sobre la práctica de aprovisionamiento de personal y sus subprocesos, reclutamiento, selección, contratación e inducción, con una visión sistémica en la que todo proceso se encuentra relacionado con otros de forma interdependiente y es el conjunto el que posibilita alcanzar los objetivos, reconociendo que la gestión humana es la piedra angular de la organización, pues afecta todo el andamiaje administrativo y la toma de decisiones organizacionales.

La comprensión de los hallazgos de la presente investigación permite señalar que las concepciones de la práctica de aprovisionamiento tienen un referente netamente funcional $y$ no estratégico (Calderón, 2004), de lo cual se constituye en un resultado que desde las investigaciones en el campo, se valora como una perspectiva limitada para la gestión humana en su papel de socia estratégica en la generación de valor agregado y sostenibilidad en el largo plazo (Wright \& McMahan, 1992; Lado \& Wilson 1994).

En este sentido, las imágenes suscitadas frente al proceso muestran representaciones sobre aprovisionamiento en las que prevalece la experiencia empírica y la intuición, la cual resulta ser suficiente para los empresarios (Calderón \& Álvarez, 2006); mientras que desde el sentir de los trabajadores, en este caso docentes, no es suficiente, ni adecuado para la satisfacción de las necesidades de la organización, ni para los empleados, tampoco para la calidad del servicio educativo en general.

Por otra parte, los valores y mitos sobre la práctica de aprovisionamiento evidencian tendencias relacionadas con la aplicación de valores, las cuales están asociadas sólo a las relaciones que se establecen en la institución, tanto entre pares como con los estudiantes, dejando de reportar aquellos valores relacionados con la responsabilidad social universitaria a la que las instituciones de educación superior están llamadas.

En cuanto a los mitos, las categorías giran en torno a los criterios de selección, la alineación entre el pensar y el hacer de la institución, es 
BÚSQUEDA - Julio / Diciembre de 2014 - No. 13 (111 - 120)

decir, la coherencia y la idoneidad profesional.

Sobre la interpretación de las categorías de la práctica de aprovisionamiento, se puede concluir que, de acuerdo con las personas vinculadas a la presente investigación, la institución no desarrolla de manera consistente los criterios técnicos, socio- humanísticos o de proyección fijados por la teoría aceptada en la gestión humana (Álvarez, 2008), al ser significada como cortoplacista, con vacíos en las estrategias explicitas y con una insuficiente visión del papel de las personas y de las ventajas de gestionar lo humano.

Lo anterior, coincide con el estado actual de las prácticas de gestión humana en Colombia, reconocido por Calderón (2006) como en estado incipiente.

Como consecuencia de lo mencionado, esta investigación planteó como objetivo la identificación de futuras líneas para la cualificación de la práctica de aprovisionamiento, y dentro de estas, se encuentran las referentes a la profesionalización y tecnificación de la selección, la potenciación de mecanismos y procedimientos de atracción y retención de talentos y la integración de la práctica de aprovisionamiento con el resto del sistema de prácticas de la gestión humana. Así mismo, exige un distanciamiento de la orientación funcional tradicional hacia una dirección más profunda del papel estratégico que el talento humano puede jugar en la empresa. Para ello se requiere tener en cuenta la dimensión relacionada con la dirección profesional de $\mathrm{RRHH}$ que incluye los procesos de selección del personal, de compensación e incentivos, y la dirección estratégica de los mismos, que a su vez incluye llevar a cabo dichas dimensiones de forma que apoye la implementación de la estrategia organizacional, que constituye la influencia más importante en el logro financiero de una organización. Las competencias estratégicas son las que impactan positivamente el quehacer de los directivos de $\mathrm{RRHH}$ y por lo tanto, requieren ser desarrolladas con más profundidad.
La gestión del talento humano busca continuamente el logro de objetivos en la organización como el aumento de la autorrealización y la satisfacción de los empleados, ayudar a la organización a alcanzar sus objetivos y realizar su misión, hacerla competitiva, suministrar empleados bien entrenados y motivados, desarrollar y mantener la calidad de vida en el trabajo, entre otros aspectos. Esto es planteado por Jaramillo (2005), como uno de los horizontes de la gestión de talento humano en las organizaciones.

Cabe resaltar que esta investigación abre nuevos interrogantes, tales como un estudio en profundidad sobre la satisfacción de los docentes universitarios, la inclusión de la gestión humana en la política nacional que rige el sistema de calidad de la educación superior en Colombia, y la investigación del impacto de la gerencia del talento humano en las instituciones de educación superior y universidades en este país.

Los hallazgos en cuanto a las representaciones sociales, maneras de pensar, creencias, opiniones y sentimientos, que tiene un grupo de docentes de educación superior sobre la selección, vinculación y contratación permiten identificar aspectos que en la práctica pueden mejorarse, comunicarse y ser útiles para el cambio representacional, la percepción de satisfacción y el desempeño docente. Las siguientes líneas de cualificación de la práctica de aprovisionamiento del personal docente están destinadas principalmente al nivel estratégico de las instituciones y especialmente a los gerentes del talento humano de las mismas:

En primera instancia, resulta de vital importancia que la gerencia del talento humano aplicada a las instituciones de educación superior sea asumida por personas competentes en el campo y que el conocimiento generado llegue hasta los ámbitos donde es requerido. Actualmente, la gestión humana ha asumido unas tendencias y retos que le exige un rol estratégico en el logro de los objetivos organizacionales, agregar valor, generar bienestar y contribuir a la alineación de los grupos de intereses. 
El cambio representacional debería ser una prioridad dentro de la agenda de trabajo de la gerencia del talento humano; sin excepción los grupos sociales generar conocimiento con la información que tienen a su disposición y de este saber común dependerá, entre otros aspectos, la expectativa de desempeño, satisfacción y compromiso con la organización.

En general, las representaciones sociales sobre la práctica de aprovisionamiento del grupo participante evidencia concepciones, imágenes, valores y mitos basados en las experiencias y vivencias, por tanto, es importante profundizar en el estudio de la vida de las personas en las organizaciones. Es notorio que en la formación representacional de la realidad intervienen los sentimientos y la interacción.

Por otra parte, los hallazgos revelan que las representaciones sociales de la práctica de aprovisionamiento se enmarcan en una gerencia del talento humano funcional, operativa, cortoplacista, intuitiva y confusa. Teniendo en cuenta que la dinámica representacional se basa en el conocimiento, las dos instituciones de educación superior deberán hacer importantes esfuerzos por cambiar sus prácticas de gestión humana y modificar actitudes, opiniones, concepciones e imágenes.

Teniendo en cuenta los hallazgos específicos, se deben fijar lineamientos de cualificación como:

De acuerdo con los participantes en esta investigación, alrededor de la estructuración del proceso de selección, incluyendo convocatoria, criterios, perfiles, manuales de procedimiento, exámenes y reglas del juego. Algunos proponen criterios y acciones específicas con relación al nuevo docente, tal como experiencia profesional y seguimiento para la cualificación y el ascenso.

De igual forma, se sugiere la revisión del proceso de contratación y sus implicaciones, pues las expectativas de los entrevistados giran en torno a mejoras salariales y a la permanencia.
En resumen, las líneas de mejora se refieren a la incursión de la gerencia del talento humano en su rol estratégico para que desarrolle y profesionalice la práctica de aprovisionamiento, la potenciación de mecanismos y procedimientos para atraer y retener talentos e integrar el sistema de prácticas de gestión humana. Es prioritario que a través de la gerencia del talento humano las personas ocupen el lugar privilegiado que les corresponde en la organización y se construya un sistema de trabajo equitativo, competitivo, responsable y sostenible.

\section{Referencias bibliográficas}

Araya, S. (2002). Las representaciones sociales: ejes teóricos para su discusión. Costa Rica: Facultad Latinoamericana de Ciencias Sociales (FLACSO).

Calderón, G. (2004). Gerencia del talento humano en el sector público: Análisis en entidades públicas de Manizales, Pereira y Armenia. Cuadernos de Administración, 71-90.

Calderón, G. (2004). Lo estratégico y lo humano en la dirección de las personas. ( $U$. d. Norte, Ed.) Revista Pensamiento y Gestión(16).

Calderón, G. (2006). La Gestión Humana y sus aportes a las organizaciones colombianas. Cuadernos de administración. Bogotá: Pontificia Universidad Javeriana.

Calderón, G. \& Álvarez, C. (2006a). Característias y sentido de las prácticas de gestión humana en pequeñas empresas. Revista Universidad EAFIT, 42(142), 26-45.

Calderón, G. \& Álvarez, C. (2007). Observatorio de prácticas innovadoras de gestión humana en la empresa colombiana. Ponencia presentada en el VIII Congreso Nacional y IV Internacional de la red de investigacion y docencia sobre innovación tecnológica. Recuperado el 2012, de http://www.uasnet. mx/ridit/Congreso2007/m1p01.pdf. 
BÚSQUEDA - Julio / Diciembre de 2014 - No. 13 (111 - 120)

Calderón, G.; Álvarez, C. \& Naranjo, J. (Julio Diciembre de 2006b). Gestión humana en las organizaciones un fenómeno complejo: evolución, retos, tendencias y perspectivas de investigación. Cuadernos Administración, 19(32).

Calderón, G.; Montes, A. \& Tobón, M. (2004). Práctica de recursos humanos y estilo estratégico en la mediana empresa: la experiencia de las empresas de Manizales, Colombia.

Farr, F. (1984). Las representaciones sociales. En S. Moscovici, Psicología Social II Pensamiento y vida social. Psicología social y problemas sociales.

Farr, R. (1984). Las representaciones sociales. En S. Moscovici, Piscología social /I Pensamiento y vida social. Psicología social y problemas sociales. Barcelona: Paidós.

Jaramillo, O. (2005). Gestión del talento humano en la micro, pequeña y mediana empresa vinculada al programa Expopyme de la Universidad del Norte en los sectores de confecciones y alimentos. Barranquilla: Universidad del Norte.

Jaramillo, O. (2005). Gestión del talento humano en la micro, pequeña y mediana empresa vinculada al programa Expopyme de la Universidad del Norte en los sectores de confecciones y alimentos. (ISSN 16576276 ed.). Barranquilla: Pensamiento y Gestión. Universidad del Norte.
Lado, A. \& Wilson, M.C. (1994). Human rosource systems and sustained competitive advantage: A competency-based perspective. Academy of Management Review, 19(4), 669-727.

López, C. (1997). Estrategias de Gestión de la mano de obra. En A. Weiss, Modernización industrial: empresas y trabajadores (págs. 239-332). Bogotá: Universidad Nacional de Colombia.

Marín, H. (Enero - Abril de 2004). La gerencia del cambio en contextos de globalización. Revista de Ciencias Sociales RCS, $\mathrm{X}^{2}(1)$, 9-27.

Pfeffer, J. (1998). La ecuación humana: La dirección de recursos humanos clave para la excelencia empresarial. Barcelona: Gestión 2000 y Edipe.

Saldarriaga, J. (Abril - Junio de 2008). Gestión humana: Human Management: Tendencies and perspectives. Estudios Gerenciales, 24(107), 137-159.

Ulrich, D. \& Lake, D. (1992). Prácticas generales: instrumentos para la acción. En D. y. Ulrico, Organizarse mejor para competir con ventaja. Buenos Aires: Vergara.

Valle, R. (2004). La gestión estratégica de los recursos humanos. Madrid: Prentice Hall.

Wright, P. \& McMahan, G. (1992). Theoretical perspectives for strategic human resource management. Journal of Management, 18(2), 295-321. 